January 2015

\title{
Rethinking Assessment: Information Literacy Instruction and the ACRL Framework
}

Melissa J. Anderson

San Jose State University, mj.anderson.garcia@gmail.com

Follow this and additional works at: https://scholarworks.sjsu.edu/ischoolsrj

Part of the Curriculum and Instruction Commons, and the Information Literacy Commons

\section{Recommended Citation}

Anderson, M. J. (2016). Rethinking Assessment: Information Literacy Instruction and the ACRL Framework. School of Information Student Research Journal, 5(2). https://doi.org/10.31979/ 2575-2499.050203 Retrieved from https://scholarworks.sjsu.edu/ischoolsrj/vol5/iss2/3

This article is brought to you by the open access Journals at SJSU ScholarWorks. It has been accepted for inclusion in School of Information Student Research Journal by an authorized administrator of SJSU ScholarWorks. Formore information, please contact scholarworks@sjsu.edu. 


\title{
Rethinking Assessment: Information Literacy Instruction and the ACRL Framework
}

\begin{abstract}
Most information literacy instruction (ILI) done in academic libraries today is based on the ACRL's Information Literacy Competency Standards for Higher Education, but with the replacement of these standards by the new Framework for Information Literacy for Higher Education, there is a need to reevaluate current teaching strategies and instructional techniques so that they can better serve the Framework's goals. This paper explores current trends in ILI instruction and in the area of assessment in particular, since ILI assessment provides an opportunity not only to evaluate teaching effectiveness but also to reinforce the learning goals of the new Framework itself. It proposes several ways that assessment strategies can be aligned with the goals of the Framework by using guided group discussion, online discussion platforms, and social media platforms, and proposes further avenues for research in the evaluation of such strategies.
\end{abstract}

\section{Keywords}

information literacy instruction, assessment, information literacy

\author{
About Author \\ Melissa J. Anderson, PhD, is an MLIS candidate at the San José State University School of Information. \\ She is passionate about teaching and believes that information literacy is the key to success for 21 st- \\ century learners.
}




\section{INTRODUCTION}

In recent years, information literacy instruction (ILI) has become an increasingly important part of the work of university librarians (Budd, 2012), and assessment of ILI sessions and stand-alone courses has become essential as libraries demonstrate the efficacy of the services they offer to university stakeholders and accreditation teams (Sobel \& Sugimoto, 2012). In addition, the information gleaned from ILI assessment allows librarians to evaluate the success of their teaching strategies and adapt lessons to perceived gaps in student knowledge, thereby improving the efficacy of future sessions (Johnson, Anelli, Galbraith, \& Green, 2011). ILI assessment has a function that goes beyond providing after-thefact data to librarians and university administrators, however. Assessment is itself a learning tool that helps students understand course content and think critically about it, all the while improving chances at retention (Haugen, 1999).

Most of the types of assessment currently being used in ILI were developed to support the Association of College \& Research Libraries (ACRL) Information Literacy Competency Standards for Higher Education (2000), which provided specific desired outcomes that could be assessed by librarians using various assessment tools. The ACRL Standards were replaced in February 2015, however, and the new Framework for Information Literacy for Higher Education (2015) places greater emphasis on student engagement with core concepts, and on questioning, collaboration, and conversation than the more discretely defined Standards did. Indeed, according to the Framework itself, the new guidelines are informed by the concept of metaliteracy, which "offers a renewed vision of information literacy as an overarching set of abilities in which students are consumers and creators of information who can participate successfully in collaborative spaces" ("Introduction," para. 4). Created with the concept of metaliteracy in mind, the Framework is meant to help educators design ILI curriculum which "demands behavioral, affective, cognitive, and metacognitive engagement with the information ecosystem" ("Introduction," para. 4). Knapp and Brower (2014) note that "Perhaps the single-largest difference between the previous set of ACRL information literacy guidelines and the proposed framework is the transition from a skill-based focus to one of knowledge-based learning and discovery" (p. 466). This shift-and the Framework itself-are not without theirs opponents (Dalal et al., 2015), but for those wishing to adopt the goals of the Framework, the shift from a focus on specific skills to one focused on the process of learning and engagement with concepts will certainly require a re-evaluation of current ILI goals and techniques.

The majority of assessment techniques used now are either objective assessments of skills or knowledge acquired, like pre- and post-tests, or summative authentic assessments such as bibliography assignments. Although both of these provide useful assessment data for administrators and library advocates, neither really helps instructors evaluate the process of learning. 
Established assessment techniques such as class discussions do provide insight into the process of learning, however, and new techniques based on internet technologies are being developed to allow students to become actively engaged with their own learning. Objective and summative assessments still have a place in ILI, but an analysis of current assessment strategies shows that they generally lack the ability to engage students deeply in a collaborative process of learning, as is encouraged by the ACRL Framework. In order to design assessment exercises that align with the learning goals of the Framework, information literacy instructors will also need to draw from a variety of contemporary, collaborative educational tools and practices, such as guided group discussions, online discussion boards, and social media platforms.

\section{KNOWLEDGE PRACTICES AND DiSPOSITIONS IN THE ACRL FRAMEWORK}

The ACRL Framework is made up of six "frames," or "interconnected core concepts": Authority is Constructed and Contextual; Information Creation as a Process; Information Has Value; Research as Inquiry; Scholarship as Conversation; and Searching as Strategic Exploration (2015,"Introduction," para.2). Each of these frames is illustrated with a set of knowledge practices, which are "demonstrations of way in which learners can increase their understanding of these information literacy concepts," and dispositions, which "describe ways in which to address the affective, attitudinal, or valuing dimension of learning" (2015; "Introduction," para. 2). The previous ACRL Standards certainly engaged some of these core concepts, and current assessment strategies also evaluate some of the knowledge practices and dispositions described by the Framework. However, the Framework is meant to define information literacy as "extending the arc of learning throughout students' academic careers" and its focus on engagement, reflection, and metaliteracy does require a certain amount of rethinking of current ILI practices. Specifically, the Framework asks faculty and librarians to "create wider conversations about student learning, the scholarship of teaching and learning, and the assessment of learning on local campuses and beyond" (2015, "Introduction," para. 6, emphasis mine). How various assessment techniques support, or fail to support, specific knowledge practices and dispositions described in the Framework is discussed below.

\section{CURRENT ILI ASSESSMENT STRATEGIES}

ILI assessment is often discussed as a part of outcomes-based education, wherein the learning goals of the students in the ILI session are articulated in advance and assessed and evaluated after the session (Flynn, Gilchrist, \& Olson, 2004). Gilchrist (2009) explains that outcomes-based educational theory was first applied primarily to K-12 education, but that the focus on the skills students needed to 
learn that came from widely adopted guidelines like the ACRL's Information Literacy Competency Standards for Higher Education led to an increased focus on student learning outcomes that could be measured with ILI assessment. Whitlock and Navanati (2013) reinforce the need to articulate clearly defined, specific, observable, and measurable learning outcomes based on the ACRL Standards before choosing assessment activities. McMillen and Deitering (2007) explain that even though the focus for assessment at Oregon State University has shifted to "learning-focused assessment" (p. 62), the process of designing ILI assessment there still begins by choosing performance indicators from the ACRL Standards and then designing assignments to test how well the students have acquired the skills in question (p. 67). From the work of these and other researchers, we can gather that many of the ILI assessments currently in use are based on specific learning outcomes identified in the now-replaced ACRL Standards, which describes specific, measurable information literacy skills that college students should have, instead of a general critical disposition towards information such as the newer ACRL Framework for Information Literacy for Higher Education proposes. Data obtained from outcomes-based assessment cannot be given up; the most recent reports from the ACRL's own Assessment in Action (AiA) program ask participating institutions to create outcomes-based assessments based on the ACRL Standards to demonstrate library value to university administrators and stakeholders (Hinchcliffe, 2015). Nevertheless, a deeper engagement with the process of student learning will require additional assessment strategies that better support the collaborative, reflective, and ongoing learning goals of the Framework.

\section{FORMATIVE VERSUS SUMMATIVE ASSESSMENTS}

Scholars of education and assessment make a distinction between formative and summative assessments. According to Whitlock and Navanati (2013), "Formative assessments happen while the learning activity is taking place, and summative assessments happen at the end of the learning activity" (p. 34). Researchers are divided on which is preferable. Dunaway and Orblych (2011) claim that by using formative assessment exercises, instructors can better understand the skills of their students and can adjust teaching strategies to address problems as they arise. Sobel and Sugimoto (2012) note, however, that the most popular tools for assessment are worksheets and quizzes given to students after an ILI session, which are summative assessments that can be used to determine what students have learned from a particular session. Similarly, Bryan and Karshmer (2013) found that by using a pre-test before and a post-test after one-shot ILI sessions, they were able to gather useful data about the specific skills and knowledge students acquired in ILI sessions. The major benefit of summative assessment is that it can provide quantifiable data about specific skills attained by students. As a 
learning tool, however, it cannot be used for "course correction" or adaptive instruction; any insights it provides will only be available after the students are gone. Even if students receive the results of their summative assessments, there is little time for self-reflection and little place for collaborative learning. Formative assessment, on the other hand, allows "students [to] become active participants with their instructors, sharing learning goals and understanding how their learning is progressing, what steps they need to take and how to take them," which aligns nicely with the goals of the Framework (Stull, Varnum, Ducette, Schiller, \& Bernacki, 2011).

\section{ObJective, Performative, AND Authentic Assessment}

Assessments can also usually be classified into one of three groups: objective, performative, or authentic. Whitlock and Navanati (2013) describe objective assessment as "focus[ing] on what students know, attempting to measure knowledge acquisition as a proxy for skill acquisition" (p. 34). Multiple-choice post-session quizzes are a typical objective assessment used in ILI. Performative assessment is assessment that tests a student's ability to perform a task, usually in a simulated situation such as filling a hypothetical information need. An authentic assessment measures the student's ability to apply skills learned in a real-world situation, often by compiling a bibliography for an actual research paper. Although Whitlock and Navanati (2013) make a distinction between these two types of assessment, across the literature performative and authentic assessments are often collapsed into one category of "performance-based assessment" or simply labeled as authentic assessment. Any of these assessment strategies can be formal or informal; formal assessments allow data to be "gathered and saved," and informal ones allow data to be collected "but not stored for later analysis" (Whitlock \& Navanati, 2013). Likewise, these types of assessments can be done at any time, either formatively or summatively, although they are most commonly used at the end of a course to capture data about the achievement of learning outcomes in the ILI session or course. Sobel and Sugimoto (2012) find that objective assessment is still the most common, but examples of performative and authentic assessment are relatively widespread in recent literature as well. Mery, Newby, and Peng (2012) use authentic assessment of student bibliographies for an English course to determine the efficacy of online ILI, and Holliday et al. (2015) find that by assessing authentic student work with a defined rubric, they can capture useful data about information literacy skills across the curriculum at their institution. Although performative and authentic assessments do allow students to demonstrate the application of skills covered in a course or session, they do not provide insight into student thought processes, nor, in most cases, do they provide opportunities for reflection or collaboration. 
Most of the literature about various types of assessment is still based fairly strictly on the learning outcomes defined by the 2000 ACRL Information Literature Competency Standards for Higher Education, and so it is somewhat difficult to determine which of these strategies would best support student learning according to the newer Framework for Information Literacy for Higher Education. What is clear about almost all of these studies, however, is that the assessment is done to determine the efficacy of the ILI, and different types of assessment tools are discussed in terms of accuracy in measuring student learning outcomes. What is rarely discussed is which of these tools contributes the most to those same outcomes, although the idea of assessment as a learning tool, and not just a tool to measure learning does appear from time to time in the literature. Hill and Kendall (2007) found that a qualitative analysis of an authentic assessment in the form of a mini clinical evaluation exercise showed that the formative assessment had a positive effect on undergraduate medical student learning, especially in terms of student motivation and attention.

\section{ALIGNING ASSESSMENT STRATEGIES WITH THE FRAMEWORK}

An analysis of how assessment strategies support the goals of the ACRL Framework for student learning should begin by looking at how assessment itself contributes to the process of learning and discovery. As stated above, summative assessments provide important information about the overall success of completed sessions or courses, and they can be very useful in demonstrating the significant contributions of the library to the overall university mission. Nevertheless, assessments meant to contribute to the process of learning, instead of measuring the outcome of learning, would need be formative by design. Since the concept of scholarship as a conversation and a collaborative process is central to the Framework, the assessment tools identified here-discussion boards, guided group discussion, and web 2.0 technologies - are all collaborative strategies. These strategies overlap to a certain degree, but they also have unique characteristics that make them well-suited to support the learning goals of the ACRL Framework.

\section{GUIDED GROUP DISCUSSION}

The advantages of discussion as a teaching strategy are well-known, and many of these advantages are aligned with the goals of the ACRL Framework. Brookfield and Preskill (2005) note that among other advantages, discussion "helps students recognize and investigate their assumptions," and "develop habits of collaborative learning" (p. 71). As the assessment is done formatively during the activity itself, it provides ample opportunity for adaptive instruction. Assessment of class discussion is often fairly informal and relies on instructor notes and observations, 
but more formal analyses are possible. Notes and observations can be collected, coded, and analyzed qualitatively to provide data for later assessment of library services. The analysis of a class or small group discussion would use techniques similar to those used for the qualitative analysis of a focus group discussion, which are commonly found in ILI literature. The use of focus group discussion for social research has some distinct advantages that are particularly useful for a study of assessment of ILI sessions. Babbie (2013) states that group discussion can be a rich source of information for researchers since "group dynamics frequently bring out aspects of the topic that would not have been anticipated by the researcher and would not have emerged from interviews with individuals" ( $p$. 157). In addition, group discussions of ILI sessions have demonstrated their ability to capture information about student thought processes that could not be captured using other methods (Markey et al., 2008; Dominguez-Flores \& Wang, 2011). Several information dispositions identified by the ACRL Framework could be cultivated by such discussions, such as developing "an open mind when encountering varied and sometimes conflicting perspectives," valuing "intellectual curiosity," and seeking "multiple perspectives during information gathering and assessment," to name only a few (2015, "Authority is Constructed and Contextual, para. 3; "Research as Inquiry," para. 4).

In addition to instructor observations and notes, discussion audits and logs can also be used to assess student learning in a group discussion, and as written assessments they can be collected, coded, and analyzed qualitatively to provide additional data for instructors and administrators. According to Brookfield and Preskill (2005), discussion audits are short written reflections on class discussions in which students note assumptions challenged, areas of confusion, and important points (p. 440). Discussion logs are similar, but shorter, and ask students to note what they learned in the discussion that they were unaware of before, what they can do now that they could not do before, and what they feel competent to teach to someone else now that they could not before (p. 444). Discussion audits and logs can be used either formatively or summatively, depending on the format of the session(s) or course, and therefore can provide a complement to the formative assessment already taking place during the discussion.

\section{ONLINE DISCUSSION BOARDS}

Already commonly used in distance learning, discussion boards provide an excellent opportunity for formative assessment of student learning, and a notable amount of literature is available on the topic of the use of discussion boards in university teaching and in ILI. According to Brookfield and Preskill (2005), "the privacy, relative isolation, and reflective space associated with asynchronous online learning enhance the development of genuinely individualistic, critical thought" (p. 375). Moreover, given the right circumstances, they find that in 
discussion board posts, "students are more likely to articulate a view that reflects their own individual thought-out position" (p. 375). Arguably, these characteristics of discussion board practice support the knowledge practice described in the ACRL Framework as "[acknowledgement that students] are developing their own authoritative voices in a particular area and [that they] recognize the responsibilities this entails, including seeking accuracy and reliability, respecting intellectual property, and participating in communities of practice" (2015; "Authority is Constructed and Contextual," para. 2). AlJeraisy, Mohammed, Fayyoumi, and AlRashideh (2015) note a number of learning advantages of online discussion boards which support this supposition, such as fostering community building, promoting research and reflection, and allowing for the inclusion of guest experts. Likewise, Matheson, Wilkinson, and Gilhooly (2012) found that discussion board use "promot[ed] questioning and sharing of information, diminished competition, and promoted collaboration" (p. 266). As assessment tools, discussion boards provide the same formative advantages of class discussion, giving instructors the ability to course correct and giving them insight into student learning processes.

Because they are written, discussion boards also provide additional opportunities for both formative and summative assessment. In their study of discussion boards in ILI, Stull et al. (2011) note that "the online environment presents opportunities for formative assessment to be conducted more efficiently by decreasing student feedback time" and that it "facilitat[es] peer-feedback and collaboration." (p. 32). Summative assessments of discussion board posts have also been successfully conducted using content analysis (Song \& McNary, 2011; AlJeraisy et al., 2015). In an analysis of discussion board use in ILI, Walton and Cleland (2014) found student contributions "embodying attributes of information literacy capability, demonstrating discursive competence in evaluating information which may lend themselves to summative assessment" (“Conclusion," para. 1).

\section{SOCIAL MEDiA PlATFORMS}

A number of Web 2.0 tools such as Facebook, blogs, and Twitter also have the potential to be used for ILI and ILI assessment. Although more research needs to be done on the pedagogical uses of social media applications, Cerna (2014) noted an increased acceptance of social applications for both communication and assessment in higher education in recent years. Drawing on the same concept of metaliteracy so central to the ACRL Framework, Witek and Grettano (2014) integrated Facebook Groups use in a rhetoric and social media course designed around information literacy. The Facebook Groups were used as an additional means of conducting discussions and assessing student understanding of core concepts. According to Witek and Grettano, the Facebook Groups provided 
"students [with] tools and a critical framework within which to understand and recover agency in their interactions with information in [social media] environments" (p. 197). Since the Facebook Groups were used all semester, they functioned well as formative assessments and allowed instructors to adapt assignments and lectures to student comments and questions. Witek and Grettano also performed rhetorical analyses of the posts in their entirety as a summative assessment when the course was completed. Witek and Grettano found evidence of several learning outcomes of the ACRL Standards in student posts, but it also seems that the use of Facebook Groups is aligned with the "Information Creation as a Process" frame of the ACRL Framework (2015), and encourages several of the knowledge practices associated with that frame, such as "articulat[ing] the capabilities and constraints of information developed through various creation processes," "assess[ing] the fit between an information product's creation process and a particular information need," and "recogniz[ing] the implications of information formats that contain static or dynamic information" ("Information Creation as a Process," para. 3). Similar to discussion boards, Facebook Groups could provide an assessment opportunity that is also a dynamic teaching strategy, and a demonstration of an information literate practice.

In a study of a student blog used as part of an information literacy module, Cmor (2009) found that the student blog had the potential to become a "usercreated reference and instructional tool, which students could go back to and consult when researching for their end of term papers" (p. 399). Since students and the instructor read, posted, and responded to the blog throughout the semester, it also allowed for formative assessment of student learning. This type of activity supports the ACRL "Scholarship as Conversation" frame. In particular, it allows students to demonstrate knowledge practices such as "contribut[ing] to scholarly conversation at an appropriate level" and "critically evaluat[ing] contributions made by others in participatory information environments" (2015, "Scholarship as Conversation," para. 3). Twitter hashtags have already been used in information literacy instruction (Alfonzo, 2014), and it may be possible to design an assessment around the creation and collection of these metatags. Such an assessment would support the "Searching as Strategic Exploration" frame, and would allow students to employ the knowledge practice "understand[ing] how information systems are organized to access relevant information" and "manag[ing] searching processes and results" (2015, "Searching as Strategic Exploration," para. 3).

\section{CONCLUSION}

According to Knapp and Brower (2014), "skills-based instruction only has temporary value to the learner, but the threshold concepts of the ACRL Framework promise a broader, more adaptive understanding of the nature of information, and better lifelong learning as a result" (p. 467). After fifteen years of basing our assessment of ILI on 
the Information Literacy Competency Standards for Higher Education and the skills demanded by those standards, the Framework presents an exciting new way of looking at information literacy and entirely new challenges to teaching it. Class discussions, online discussion boards, and social media platforms are all being used for ILI already, and therefore using these tools for assessment is really a matter of looking at them through a new lens rather than inventing a new technique. With the ACRL Framework as a guide for ILI assessment design, the line between the teaching practice and the assessment strategy becomes blurred, but that blurring is actually part of the Framework's objective in encouraging students to collaborate and to reflect on their own learning. Although evidencebased data drawn from objective, summative assessments will still be necessary for library advocacy, accreditation reports, and other purposes, the Framework specifically asks us to recognize the "greater role and responsibility in creating new knowledge" that students have now, and it challenges librarians and faculty to design new curricula, assignments, and assessments that enlarge understanding and enhance engagement with concepts. Group discussion, online discussion boards, and social media platforms are just a few of the tools that can be employed as we rethink how we assess student learning and contribute to the very learning outcomes we are assessing. More research is needed on how these and other assessment strategies can promote the goals of the ACRL Framework while still providing valuable data to administrators, and the areas of learning analytics and educational data mining show great promise for capturing this type of data. (Ming and Ming, 2015). The Framework reminds us that "scholarship is an ongoing conversation in which information users and creators come together and negotiate meaning" (2015, "Scholarship as Conversation," para. 1). Now that the Framework has been adopted, we can begin the conversation about how to align ILI assessment to its goals.

\section{REFERENCES}

Alfonzo, P. (2014). Using Twitter hashtags for information literacy instruction. Computers in Libraries, 34(7), 19-22.

AlJeraisy, M.N., Mohammad, H., Fayyoumi, A., \& AlRashideh, W. (2015). Web 2.0 in education: The impact of discussion board on student performance and satisfaction. The Turkish Online Journal of Educational Technology, 14(2), 247-260.

Association of College \& Research Libraries (ACRL). (2015). Framework for Information Literacy for Higher Education. Retrieved from: http://www.ala.org/acrl/standards/ilframework

Association of College \& Research Libraries (ACRL). (2000). Information Literacy Competency Standards for Higher Education. Retrieved from: 
http://www.ala.org/acrl/sites/ala.org.acrl/files/content/standards/standards. pdf.

Brookfield, S.D. \& Preskill, S. (2005). Discussion as a way of teaching: Tools and techniques for democratic classrooms. San Francisco, Calif.: JosseyBass.

Bryan, J.E. \& Karshmer, E. (2013). Assessment in the one-shot session: Using pre- and post-tests to measure innovative instructional strategies among first-year students. College and Research Libraries, 74(6), 574-586. Retrieved from: http://crl.acrl.org/content/74/6/574.full.pdf+html.

Budd, J.M. (2012). The changing academic library: Operations, Culture, Environments. Chicago, Ill.: The Association of College \& Research Libraries.

Cerna, M. (2014). Trends in the acceptance of social software applications in higher education. A case study. Proceedings of the European Conference on e-Learning, 121-129.

Cmor, C.C.D. (2009). Blogging towards information literacy: Engaging students and facilitating peer learning. Reference Services Review, 37(4), 395-407. doi:_10.1108/00907320911007001.

Dalal, H. et al. (2015, January 7.). An open letter regarding the Framework for Information Literacy for Higher Education. [Blog post]. Retrieved from http://acrlog.org/2015/01/07/an-open-letter-regarding-the-framework-forinformation-literacy-for-higher-education/.

Dominguez-Flores, N. \& Wang, L. (2011). Online learning communities: Enhancing undergraduate students' acquisition of information skills. The Journal of Academic Librarianship, 37(6), 495-503. doi:10.1016/j.acalib.2011.07.006.

Dunaway, K.M. \& Orblych, M.T. (2011). Formative assessment: Transforming information literacy instruction. Reference Services Review, 39(1), 24-41. doi: 10.1108/00907321111108097.

Flynn, C., Gilchrist, D. \& Olson, L. (2004). Using the assessment cycle as a tool for collaboration. Resource Sharing \& Information Networks, 17(1/2), $187-203$.

Gilchrist, D. (2009). The twenty-year path: Learning about assessment, learning with assessment. Communications in Information Literacy, 3(2), 70-79.

Haugen, L. (1999). Strategies to check student learning in the classroom. Iowa State University Center for Excellence in Teaching and Learning. Retrieved from: http://www.celt.iastate.edu/teaching-resources/classroompractice/teaching-techniques-strategies/check-student-learning/.

Hill, F., \& Kendall, K. (2007). Adopting and adapting the mini-CEX as an undergraduate assessment and learning tool. The Clinical Teacher, 4(4), $244-248$ 
Hinchcliffe, L. (2015). Assessment in Action: Academic Libraries and Student Success. [Slides]. Retrieved from http://connect.ala.org/files/ACRL\%20open\%20forum\%20Feb\%202015\%2 Oweb.pdf.

Holliday, W., Dance, B., Davis, E., Fagerheim, B., Hedrich, A., Lundstrom, K., \& Martin, P. (2015). An information literacy snapshot: Authentic assessment across the curriculum. College and Research Libraries, 76(2), 170-187. Retrieved from: http://crl.acrl.org/content/76/2/170.full.pdf+html.

Johnson, C.M., Anellli, C.M., Galbraith, B.J., \& Green, K.A. (2011). Information literacy instruction and assessment in an honors college science fundamentals course. College and Research Libraries, 72(6), 533-547. Retrieved from: http://crl.acrl.org/content/72/6/533.full.pdf+html.

Knapp, M. \& Brower, S. (2014). The ACRL framework for information literacy in higher education: Implications for health sciences librarianship. Medical Reference Services Quarterly, 33(4), 460-468. doi: 10.1080/02763869.2014.957098.

Markey, K., Swanson, F., Jenkins, A., Jennings, B.J., St. Jean, B., Rosenberg, V., . . Frost, R.L. (2008). Designing and testing a web-based board game for teaching information literacy skills and concepts. Library Hi Tech, 26(4), 663-681.

Matheson, R., Wilkinson, S.C., \& Gilhooly, E. (2012). Promoting critical thinking and collaborative working through assessment: Combining patchwork text and online discussion boards. Innovations in Education and Teaching International, 49(3), 257-267.

McMillen, P. \& Deitering, A.M. (2009). Complex questions, evolving answers: Creating a multidimensional assessment strategy to build support for the "teaching library." Public Services Quarterly, 3(1/2), 57-82.

Mery, Y., Newby, J. \& Peng, K. (2012). Performance-based assessment in an online course: Comparing different types of information literacy instruction. portal: Libraries and the Academy, 12(3), 283-298. doi: 10.1353/pla.2012.0029.

Ming, N.C. \& Ming, V.L. (2015). Visualizing and assessing knowledge from unstructured student writing. Technology, Instruction, Cognition, \& Learning, 10(1), 27-44.

Sobel, K. \& Sugimoto, C.R. (2012). Assessment of learning during library instruction: Practices, prevalence, and preparation. The Journal of Academic Librarianship, 38 (4), 191-204. doi: 10.1016/j.acalib.2012.04.004. 
Song, L. \& McNary, S.W. (2011). Understanding students' online interactions: Analysis of discussion board postings. Journal of Interactive Online Learning, 10(1), 1-14.

Stull, J.C., Varnum, S.J., Ducette, J., Schiller, J., \& Bernacki, M. (2011). The many faces of formative assessment. The International Journal of Teaching and Learning in Higher Education.23(1), 30-39.

Walton, G. \& Cleland, J. (2014). Information literacy in higher education -empowerment or reproduction? A discourse analysis approach. Information Research, 19( 4), 229-231.

Witek, D., \& Grettano, T. (2014). Teaching metaliteracy: a new paradigm in action. Reference Services Review, 42(2), 188-208. doi: 10.1108/RSR-072013-0035.

Whitlock, B. \& Nanavati, J. (2013). A systematic approach to performative and authentic assessment. Reference Services Review, 41(1), 32-48. doi: 10.1108/00907321311300866. 